\title{
Texts on Translation and Translational Norms in Bengal
}

\section{Subha Chakraborty Dasgupta}

\begin{abstract}
Translation Studies in India has begun to take institutional shape and it is important at this juncture to collate texts on translation written in Indian languages at different points of time. This would not only facilitate our understanding of translational norms acting in the literary and linguistic system at any given point of time, but also lead to a general notion of attitudes related to translation as process and product in a particular system. This in turn will enable us to build our theories of inter-lingual translation. In this paper I will draw attention to a few such texts in Bangla in what has been called the modern period in literary fistory.
\end{abstract}

Translation in Bangla, as in the case of other Indian languages, has a long history going back to ancient times and whether or not in the early stages they were looked upon as 'translation' is a different matter. In fact, as Dinesh Chandra Sen points out in his article "Bangla Bhashay Anubad-Sahitya" (Sen 1907:18:2\&3), the very course of Bangla language was deflected towards Sanskrit again in the early stages because of the profusion of Sanskrit words in the translated versions of the Ramayana, the Mahabharata and the Bhagvat Purana. These texts were very popular and hence had an impact on the common language of the people. Sen further gives the example of Alaol's Padmabati in the mid- $17^{\text {th }}$ century, translated from the Hindi Padumavat of Jaysi, as having the greatest number of Sanskrit words. The translation, accomplished while Alaol was in service in Arakan, was found, Sen

Translation Today Vol. 3 Nos. 1 \& 2, 2006 @ CIIL 2006 
states, in the Persian script in Chittagong. Numerous such instances may be there of the curious passage from one language into another of a popular text in India. There was also the case of translations from Arabic, Persian and Sanskrit tales into simple Hindusthani that were again very popular and had a great impact on the language and literature of the people. The translation scene, however, changed quite radically in the middle of the nineteenth century with the encounter between two very different linguistic and literary systems, Bangla and English, within asymmetrical power relations. In 1851, the Vernacular Literature Committee (later renamed Society), a semi-governmental institution was set up by Drinkwater Bethune, with help and co-operation from British and Indian scholars. In Bangla the society was called Bangabhasanubadak Samaj or Society for Bangla Translation. In the preface to the first text Lord Clive (1852) published by the society, the author Harachandra Dutta wrote that "the object of the association is distinctly stated to be, not only to translate but to adapt English authors into Bengali" (quoted in Sukumar Sen, 1975:43). We can recognise the statement as laying out a colonialist project aimed at obliterating elements in the literary system and remoulding with an overarching purpose. The project however, was only partially successful, for in practice, the society produced translations not only of British texts, but also of texts from other literatures through English and from Indian literatures. However, the kind of literature that was translated, moral tales and social allegories, led to the production of similar texts in the original, gradually bringing in dichotomies and changes in the value system. But again, from a different point of view, activities of the society also contributed to significant changes in the use of the Bangla language that, along with other factors, led to the creation of masterpieces in prose in the next few decades. It would be an interesting study to see how these changes were necessarily very different from those brought about in the early stages of translation from Sanskrit into Bangla. 
My concern in this paper is with the modern period and the translation of poetry where one does not encounter any overt prescriptive agenda imposed from above as in the case of prose. In an indirect manner, however, through English education chiefly, an entire school of poetry gets adapted and some translated, though it is not until the first decades of the twentieth century that anthologies of translated poems appear. Here again we come across a large range of source language texts and various different attitudes towards what we would call translational norms, and our understanding of translation as activity in Bengal would be incomplete if we read it solely in terms of a colonial paradigm.

During the second half of the nineteenth century, and the first few decades of the twentieth century to a certain extent, one comes across a large number of poems that are called adaptations, literally chhaya abalambane (in the shadow of) and quite often the language is mentioned, but not the name of the poet or the poem. A comparison with the source language text of some of the poems would reveal a strong presence of an invariant core, and this, according to Gideon Toury, would allow the poem the legitimacy of a translated text. In others one may find just a distant echo of the original, although this is rare. The phenomenon may also suggest that the concept of translation as an activity that involves the decoding of a message in a particular language/literary system and encoding it in another, taking into account the denotative and the connotative elements of the message in the sphere of poetry, has not yet taken any definite shape. Yet again, the attitude also has at its point of origin an idealistic, universalistic notion of poetry that shapes horizons of poetic activities in the literary system and this despite experiences of colonialism over a long period of time. It is universalism with a difference as articulated by Rabindranath in his speech 'Visvasahitya' or World Literature delivered in 1906. There he talks about his view of literature as one constituting a world of its own, where each single work contributes to the perfection of the 
whole. He feels that man realised himself, fulfilled himself in knowing others, in bringing them closer or working for them. It was this truth or essence of man that tried to express itself through literature and hence one could conceive of literature in terms of a whole where each literary work played its part in realising the perfection of the whole. Rabindranath does speak of one literature, of essences and truths, but what lends a different dimension to his theory of essences and truths is the fact that they are contingent on human relations. The thought process is open-ended - the creation of the literary tower forever remains incomplete with just the ideal of the end stamped on its innermost core. Within this framework the translational norm will also be open-ended enough to include free adaptations of poems that can belong anywhere and to all.

Rabindranath's vision of visvasahitya finds resonance in many of the poet-translators of the period. The first collections of world poetry in Bangla were Tirthasalil (1908), Tirtharenu (1910) and Manimanjusha (1915) and their author Satyendranath Dutta. There were five hundred and three texts from different periods and countries. Translations were made from Chinese, Persian, English, French, and from several Indian languages. In one of the earlier poems Satyendranath seems a little unsure of the end-product, "I do not know what I did in the context of what I had set out to do" (1984:123). The pre-translational phase, one governed by the ideology of faithfulness and by visions of precise contours, soon gives way to other exigencies, more immediate perhaps, more necessary to the literary system. The leading poets of the period encourage Satyendranath in his efforts to translate - Rabindranath tells him after reading Tirtharenu that his translations are not silpakarya (artifacts), but sristikarya (creative acts). Earlier after reading Tirthasalil, he had written that the translated poems had taken shelter in the branches of the original to blossom in all their beauty and rasa. The translation of a poem was in fact, he writes, both a translation and a new poem. In other words, the translated poem also had to be accepted as a poem in the target literature to 
legitimise its entity as a translated poem. In Satyendranath's translations there is a strong presence of the source language poem in the general ambience and the form which are again layered with cultural and local connotations. There are also the demands of the creative act - once a choice has been made with reference to one particular texteme, others necessarily have to follow. As a poet, Satyendranath occupies an important place for his experiments with sound patterns, and often as translator, he finds an incentive in source language poems to explore such patterns. The Japanese tanka and the Malaysian pantoum, the verse patterns of Paul Verlaine and Victor Hugo and certain metrical patterns of Sanskrit poetry are introduced in Bangla through his translations. As for the act of translation, he says he engages with it to bring about a relationship of ananda or joy (anander atmiyata korite sadhan).

Satyendranath Datta belongs to the pre-modern period in Bangla literature, if we go by standard periodisation in histories of literatures. Translation activities continue on a large scale during the several decades of transition from the pre-modern to the modern. Poets, especially from the mid-twenties, try to come out from the dominant presence of Rabindranath, to find new means of expression as they grapple with the times, the aftermath of the First World War, the economic depression and the resultant instability. Translation activities at this point of time get linked with the uncertainties of social life and receive a new stimulus. Anthologies of translated poems by single authors are published a little later in the fifties, but journals such as Parichay, concentrating to a large extent on foreign literature, emerge. The poetry of the period becomes marked by an intertextual quality that becomes both the sign and symptom of modernity. As Alokeranjan Dasgupta and Sankha Ghosh write in the preface to their volume of translated poems Sapto Sindhu Das Diganto, translation during the period is an integrated activity, for the source language poem is not felt to be a very distant entity, whereas in earlier periods source language poems 
were translated for the sake of beauty and variety or, in other words, not because they complemented one's sense of being in the world. In fact, to many poets writing at the time, translation becomes a necessary act. If we do not have as many adaptations (chhaya abalambane) as in the last few decades, we have Bangla poetry, or at least one prominent stream of Bangla poetry being compulsively drawn into a larger arena of world poetry. The notion of difference, strongly present but unstated in the concept of visvasahitya, is glossed over at least on the surface level. Translation then supposedly has an active place in modelling the target system. Sudhindranath Dutta writes an essay called 'Kavyer Mukti' or the 'Emancipation of Poetry' where he emphasises the need for an openended process of reception. The very act of translation gets linked with the writing of poetry. On the pragmatic level this can imply greater degrees of equivalence between content or semantic categories as well as metalinguistic or cultural and semiotic aspects. Given the differences in the two systems this happens within certain limits and to the extent that it does it also brings in a gap between the popular and the cultivated circuit of readers of poetry. In the next section, I will take up texts on translation by three important poettranslators of the period.

I will go back to Sudhindranath Datta, an important poettranslator of the period who believes that the ground for creating poetry is not as fertile as before and so the poet has to roam the entire world and gather seeds that can germinate into poetry. In his introduction to his volume of translated poems Pratidhvani (1954) he takes up the notion of translation and states that poetry is untranslatable - it is impossible to create the same poem in another language at another time and in another place and especially where the systems are as different from each other as for instance, Bangla and French. Yet he translates. His translations of Mallarmé's 'L'après-midi d'un faune' and of Valéry's 'L'ebauche d'un serpent' have been acclaimed as poems of considerable achievement. The first has a hundred verses of the same length with end rhymes, while 
the second has thirty-one stanzas of ten short and equal lines with a complex rhyme scheme. Datta also has a detailed note on Mallarmé's poem suggesting that the venture had been undertaken as a kind of exercise in difference - an attempt to reach some kind of an endpoint, a limit to which poetry could aspire, to the empty core of music or to the ideal of absence. It is a certain concept of poetry that would then seek to find expression in the translated poem. The volume also has twenty-three sonnets of Shakespeare and several poems of Heine. Datta tries to find a way out of his own argument that since poetry is the exact correspondence of word and experience it is untransferable, by saying that in the case of a translated poem it is the experience of the source language poem that is substituted for primary experience. Again later he says that translation is a creative act undertaken as a means of self-expression. The success of the translated work, he feels, depends on the means adapted for selfexpression. What he means is that translation engages with form and style, rather than with semantic content - the latter is important in as much as it is a part of the form, but not as a central preoccupation. The translational norm then encompasses a holistic perspective including the poem and the history of poetic form as such. It is within this broader view of poetry that the translational act becomes crystallised. It will be a faithful translation from the point of view of the overall experience or the elicitation of rasa and an independent poem in literary history, looking both to the past and the future, carrying within it the possibilities and potentials of further explorations in form and syntax, something that may bear fruit in the poet's own poems. Some parts of Datta's famous poem 'Jajati', Buddhadeva Bose points out, is a happy blend of translation, reception and creation.

Moving from the general to the personal, Datta uses a complex symbol to describe his status as a translator. Although, he states, his translations can never reach the heights achieved by the source language poems, by constant revisions and rewritings, he is 
able to achieve the status of Ekalavya. It is history that makes him use the symbol that he does, but history is not a determining force, for the symbol is evocative of both pride and humility, the former more perhaps than the latter. There is a double vision in Sudhindranath's concept of the translator as Ekalavya - a strong attempt to excel in conveying the experience of the source language poem on the one hand, and on the other, the consciousness of having achieved excellence as a poet, of a sense of fulfilment that will lead to other directions, other poems and other poets, create a tradition that will link up with his own as well as with the tradition of European poetry from which he draws.

Commenting on the act of translation with reference to Sudhindranath Datta's translations in 'Kabitar Anubad o Sudhindranath Datta' (1957) Buddha deva Bose, an eminent poettranslator, says translational activity implies training in discipline and self-restraint (a point mentioned earlier also by Datta) as well as what he calls atmasuddhi or purification of the self. The latter may signify that labour undertaken for the sake of poetry in a somewhat detached manner, as a kind of sadhana, with the self in the background, leads to purification. The task of the translator gets invested with a value code from a spiritual domain. In fact, he often envisions a deep relationship with the source language poem. He states that in order to "get hold of the poem, one has to merge with it, give a part of oneself to it. This great union can be called translation" (ibid. 1957:167). The discourse on translation that we encounter in Bose is symptomatic of a general trend in engaging with translation where one tries to understand the nature of the activity from an ontological point of view, sometimes with reference to the creative impulse, as most of the translators are also poets. There is an inward turn -a self-reflexivity with reference to the creative, situated within kavyatatva, or Indian poetics, that is present in a diffused manner in the literary system. It is the poet, Bose says, who is the natural and legitimate translator of poetry. With the right combinations, the act undertaken by a poet will be creative and not 
simply constructive. He also talks of the poet using a source language text as a mask for himself and so his translation is often not just a translation, but in fact a rival poem. He compliments Sudhindranath not for a faithful series of translated poems, but for having added a group of "heartwarming" poems to the repertoire of Bangla poetry.

There is also a movement towards the objective, the pragmatic area of discourse when he begins to engage with actual target language texts. He voices his reservations about the domestication of source language texts on cultural levels. A translational experience demands that a lilac should remain a lilac and the Alps should not to be transformed into the Himalayas. But he is willing to temporarily withdraw his reservations because of the gift of certain poems such as 'Parivad', scintilating with rasa. Bose, incidentally, also quotes from various European poets and translators on translation. There are changes in translational norms, as exemplified by Sudhindranath's and Buddhadeva's analysis of metrical patterns in different language systems with reference to dependability, but this is so only in the case of the discourse on translation while actual practice foregrounds creativity, recognises, in the words of Bishnu Dey, that the equation is far more complex than that of a simple mathematics of one and two, involving as it does rupa and guna, rasa and prem or love (Dey 1965:1-97).

Buddhadeva's greatest achievements in the area of translation are his renderings of Kalidasa's Meghadutam, Baudelaire's Les fleurs du mal and the poems of Holderlin and Rilke. In the context of Kalidasa's translation, he states that it is the translator's task and the translator's alone, to make ancient writers and their works an integrated part of contemporary literature. There are also numerous references to European literature in his article where he thinks the ancient literary tradition manifests itself as a vital part of the modern because of an uninterrupted history of 
translations of ancient texts. Here he attests to the fact that translated texts while being discrete units are also parts of a larger whole contributing to a certain extent in giving shape to contemporary texts and/or investing them with a certain depth and perspective.

While translating Baudelaire's Les fleurs du mal, Bose gives detailed annotations along with a chronological sequence of events in Baudelaire's life and a separate date chart of literary events in France during his time. He reconstitutes the period in which Baudelaire was writing to prevent any unilinear or single dimensional reading of the poems. It is important to create a frame within which the act of translation takes place - and the act itself becomes a linguistic event with metalingual dimensions within a macroevent of cultural reconstruction. The latter is related primarily to the source culture, but works in the context of the target culture as well. Baudelaire's poetry, Bose feels, extracts and conveys the essence of poetry while divesting it of all that is inessential. Translating his poetry then would be an important literary task, an exploration of language and what it can achieve, an exercise that would be functional in different ways in literary history. The actual translations give us poems in Bangla that bear traces of a different kind of poetic sensibility - they introduce new elements to Bangla literature by bringing in the face of the base and ugly in poetry and by creating new expressions of suffering. It is Baudelaire suitably adapted to a different space and time and to a certain extent, reworked in accordance with the personal predilections of the poettranslator. Les fleurs du mal is a book of poems that takes one on an evocative voyage through some of the most desperate, vile and loathsome images of modern life. The poetic form in Bangla is not ready to carry across certain experiences, as language and form answer in a very complex manner to what can or cannot be expressed in a particular community at a particular time. Hence, "Il est des parfums frais comme des chairs des enfants/ Doux comme les hautbois, verts comme les prairies" (Baudelaire 1954:14) (There are perfumes fresh as the flesh of infants/ soft as the oboe, green as 
the prairies) becomes "Kono kono gandho jeno organer nisvane komol/ prairier sabuje makha, sisur parase sukhomoy"(1969:39) (Some perfumes are soft in the sound of the organ/ covered with the green of prairies, pleasurable with the touch of infants). The metaphoric rendered into the non-metaphorical has taken away the extension in space and time as well as the nameless violence of the first verse, but the invariant core of synaesthetic experience has been preserved and it is this that would be functional in literary history.

In his introduction to Les fleurs du mal, Buddhadeva Bose explains that as we had been confined within English literature for a long period our consciousness of world literature as well as of English literature remained incomplete. In order to appreciate any literature it was important to be aware of related literatures and of the multiliterary factors acting upon it. Translation was a kind of decolonising activity for him in that it led to a decentering of primary channels of influence and reception.

Bishnu Dey, the third poet-translator in this study, has made various statements on different occasions regarding the act of translation, but I will simply take up a word that he uses in the context of translation and that word is anubadsambhavyata or 'translatability'. Dey is an important poet translator who talks about why certain poets and their ideas had been important to him. Eliot's method, his formal devices, Dey states in an essay on the poet (1948), are of great help to him as he writes despite the fact that they inhabit different worlds. He further states, that it is because of the "underlying freedom of the symbolist method... that a Christian poem receives translatability (anubadsambhavyata) in memory of Gandhiji's second movement, 'Coriolan' in the period of the interim government, 'Gerontion' suddenly appears in the twilight of the merged adaptation-translation period when Gandhiji protests through fasts and young boys and girls lay down their lives in processions to protest against the insane murders taking place in Calcutta." The 
word anubadsambhavyata throws open a whole range of contexts within which the act of translation receives maturation. There is the context of historical configurations where translation would play an interactive role in grasping and consequently giving voice to the experiences of the given moment. A sense of solidarity established through translation also underlies the examples that Bishnu Dey offers, for each of them articulates a situation of oppression. This is a phenomenon that one encounters quite often in the history of translation in Bengal, in Bishnu Dey's own translation of socialist poets, as well as generally, in translated collections of anti-fascist poetry, for instance. What is important in Bishnu Dey's statement again is the fact that translation is not simply a transfer from one language to another, but also from one event to another, bringing new contexts of understanding to an event in another culture.

The word 'translatability' also takes us back to Walter Benjamin's essay "The Task of the Translator: An Introduction to the Translation of Baudelaire's Tableaux Parisien":

"Translation is a mode. To comprehend it as mode one must go back to the original, for that contains the law governing the translation, its translatability... Translatability is an essential quality of certain works, which is not to say it is essential that they be translated: it means rather that a specific significance inherent in the original manifests itself in its translatability" (Benjamin 1969:72).

Benjamin's statement also pointed to a continuous renewal and transformation of the original in translation. He stated that the purposefulness of the process was to be sought in a higher sphere, "the ultimate purpose towards which all single functions tend is sought not in its own sphere, but a higher one." It is here that the "suprahistorical kinship" of languages enters. Bishnu Dey's anubadsambhavyata brings us back from the suprahistorical to the 
present in a very concrete manner - fills out a speculative continuum with a segment of an intense presence. For instance, if we look at 'Coriolan'- " Look / There he is now, look: There is no interrogation in his eyes / Or in the hands, quiet over the horse's neck / And the eyes watchful, / waiting, / perceiving, / indifferent" (Dey 1969: 127)and place it in the context of the freedom movement in India we understand that translatability involves a clearer grasp of the present, the struggle for independence, the chaotic times and an ability to articulate and hence have a grasp over history. And again translatability does not only pertain to a newer comprehensibility, a different understanding of the particular, but also takes one back to other contexts of meaning and hence opens up further possibilities of future relationships with yet other similar contexts. Dey is moving towards a larger sphere of purposefulness that lies in a different conceptualisation of literature and that gets assimilated with the concept of translation. Translational norms are then formulated with reference to both old and new systems of aesthetics operating in the sphere of Bangla poetry.

\section{REFERENCES}

Baudelaire, Charles 1954 "Correspondences" in Les fleurs du mal Paris: Garnier Freres.

Benjamin, Walter 1969 Illuminations (tr) Harry John New York: Schocken Books.

Bose, Buddhadeva 1957 "Kabitar Anubad o Sudhindranath Datta" in Swades o Sanskriti Calcutta: Bharavi.

1961 "Pratisanga" in Charles Baudelaire Calcutta:

Dey's Publishing.

Datta, Sudhindranath 1962 "Preface to Pratidhvani" in Sudhindranath Datter Kabyasangraha Calcutta: Bharavi. 
Dey, Bishnu 1965 "Rabindarnath O Silpa-Sahitya Adhuniketar Samasya" Sahityapatra Saradiya.

1997 "Thomas Stearns Eliot" in Bishnu Dey Prabandha Sangraha (Vol I) Calcutta: Dey's Publishing.

Dutta, Satyendranath 1984 "Samapti" in Aloke Ray (ed) Satyendranath Kabyagrantha Calcutta: Sahitya Samsad.

Eliot, T.S. 1969 'Coriolan' in T.S.Eliot: The Complete Poems and Plays London: Faber \&Faber.

Sen, D.C. 1907 "Bangla Bhashay Anubad-Sahitya" in Sahitya 119$125 \&$ 145-153, Vol.18:2\&3.

Sukumar Sen 1975 Bangla Sahityer Itihas 43 ,Vol III.

Toury, Gideon 1980 "The AdeQuate Translation as an Intermediating "Language": A Stylistic Model for the Comparison of a Literary Text and its Translation" in Actes of the VIIIth Congress of the International Association of Comparative Literature. 
